\title{
Sistema unificado para rastreamento de cargas e produtos
}

\author{
Jaqueline R. Oliveira*, Leandro R. Ximenes.
}

\section{Resumo}

Esse projeto tem a intenção de apresentar uma possível solução para os problemas de roubos e furtos de objetos e cargas. A ideia é desenvolver um sistema para rastreamento de forma que seja possível implementar as principais tecnologias de rastreamento em um mesmo ambiente. Para isso, notou-se que, o uso de um tipo de código serial para a identificação do produto pode ser uma boa alternativa para o desenvolvimento de um sistema desse tipo.

Palavras-chave: Sistema de rastreamento, RFID, sistema unificado.

\section{Introdução}

Rastrear é o ato que capturar uma determinada ocorrência ou informação durante um percurso, sendo assim, é possível registrar essas ocorrências e formar um histórico de todos os pontos de captura de informações. Esse tipo de serviço tem importantes aplicações para fins de segurança e logística podendo de tornar alguns processos mais eficientes. Com os frequentes problemas de roubos e furtos de cargas [1] e objetos de valor [2], é notável a importância dos sistemas de rastreamento e monitoramento no mercado globalizado, sendo um serviço relevante para os públicos industrial, comercial e individual.

As principais tecnologias de rastreamento atualmente são o GPS, RFID e Bluetooth, sendo que cada tecnologia possui em sistema específico para tratamento de dos dados coletados. Existem também os métodos próprios de algumas empresas, como a empresa Correios, por exemplo, ela utiliza um código serial chave para que o cliente possa obter acesso as informações do produto em um ambiente online. É possível perceber que cada método de rastreamento é direcionado a um tipo específico de produto, sendo assim, ao desenvolver uma ideia sobre a relação entre identificar e rastrear, nota-se que o processo de rastreamento se torna mais simples quando se trata de algo já identificado.

Sendo assim, para consolidar os sistemas de rastreamento em um sistema unificado, a ideia do projeto é incluir de um código serial para identificação de produtos em um QR code, dessa forma, esse código será vinculado as tecnologias de identificação (RFID, Bluetooth, QR Code, Bar Code).

\section{Resultados e Discussão}

Ao estudar quais seriam os requisitos para um sistema de rastreamento unificado, a conclusão é que o ato de identificar um objeto já é uma forma de rastreamento, no caso de um rastreio por Bluetooth tem-se o reconhecimento de um dispositivo leitor com uma etiqueta, para um sistema com RFID o leitor detecta (identifica) a etiqueta. Para consolidar o sistema para rastreamento, a ideia é utilizar um código serial para a identificação de itens, dessa forma, cada objeto é de identificado por esse código unificado que é vinculado a uma tecnologia de rastreamento.

O código serial, utilizado para consolidar esse sistema é composto por outros códigos de identificação já existentes, pois, dessa forma é possível aplicar em vários tipos de objetos, além disso informações sobre o tipo de rastreamento usado, país e alguma informação adicional também é parte no espoco do código criado para sistema. Para que processos como por exemplo um cadastro de produto em loja seja mais fluido, esse código serial será escrito em um QR code.

Uma parte importante do projeto, é pensar em rastreamento como uma forma de identificação ponto a ponto. Assim, nota-se que pode ser interessante acumular essas informações no código serial do produto, pois dessa forma o código conterá tanto informações do produto em si, como também informações sobre onde esse produto passou, como um histórico do produto. A figura 1 mostra um exemplo genérico desse código serial e dessa ideia de acumular informações ponto a ponto. Um sistema unificado pode ser vantajoso, um exemplo, seria a redução de burocracia no sistema de alfandega em casos importações, a facilidade para controle de estoque reduzindo a mão de obra para a fiscalização de produtos.

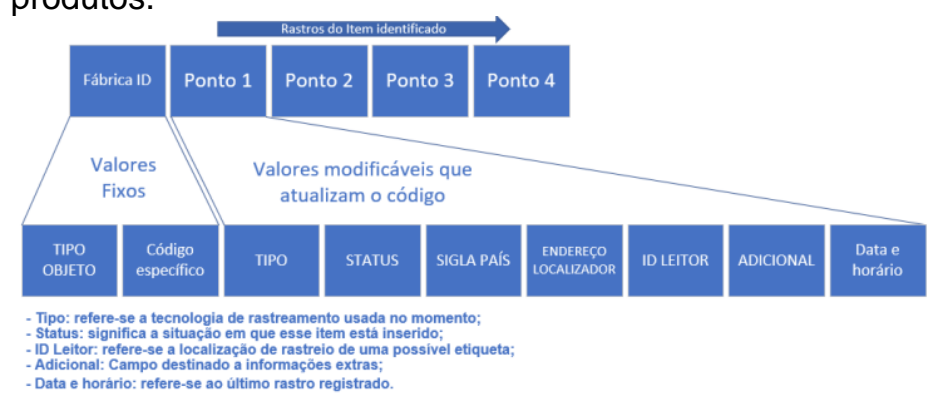

Figura 1. Código serial genérico.

\section{Conclusões}

Esse projeto tem o objetivo de apresentar uma ideia alternativa de sistema, que pode facilitar os processos de rastreamento e monitoramento de produtos em geral. Com a inclusão de um código serial para a identificação de itens escrito em um QR code, tem-se a possibilidade de que processos como a taxação de produtos em alfândega facilitada, pelo fato do código já conter algumas informações prévias do produto. Enfim, as possibilidades de aplicação são bastante abrangentes, assim como as formas de implementar um sistema desse tipo.

1 AGÊNCIA NACIONAL DE TELECOMUNICAÇÕES. Brasil bloqueia 9,1 milhões de celulares por roubo, furto ou perda. Disponível em: < https://www.segs.com.br/seguros/72033-reajuste-no-seguro-de-transporteimprevisibilidade.html>. Acesso em: 20 jan. 2019.

2 FIRJAN. Quanto custa o furto e roubo de cargas no Brasil. Disponível em:< http://www.firjan.com.br/lumis/portal/file/fileDownload.jsp?fileId=2C908A8A 5A91C255015AD730A23955B8>. Acesso em: 20 jan. 2019 